2018-04-16

\title{
Chemolithoheterotrophy: Means to Higher Growth Yields from this Widespread Metabolic Trait
}

\section{Boden, Rich}

http://hdl.handle.net/10026.1/11881

\author{
10.1007/978-3-319-39782-5_51-1 \\ Springer
}

All content in PEARL is protected by copyright law. Author manuscripts are made available in accordance with publisher policies. Please cite only the published version using the details provided on the item record or document. In the absence of an open licence (e.g. Creative Commons), permissions for further reuse of content should be sought from the publisher or author. 


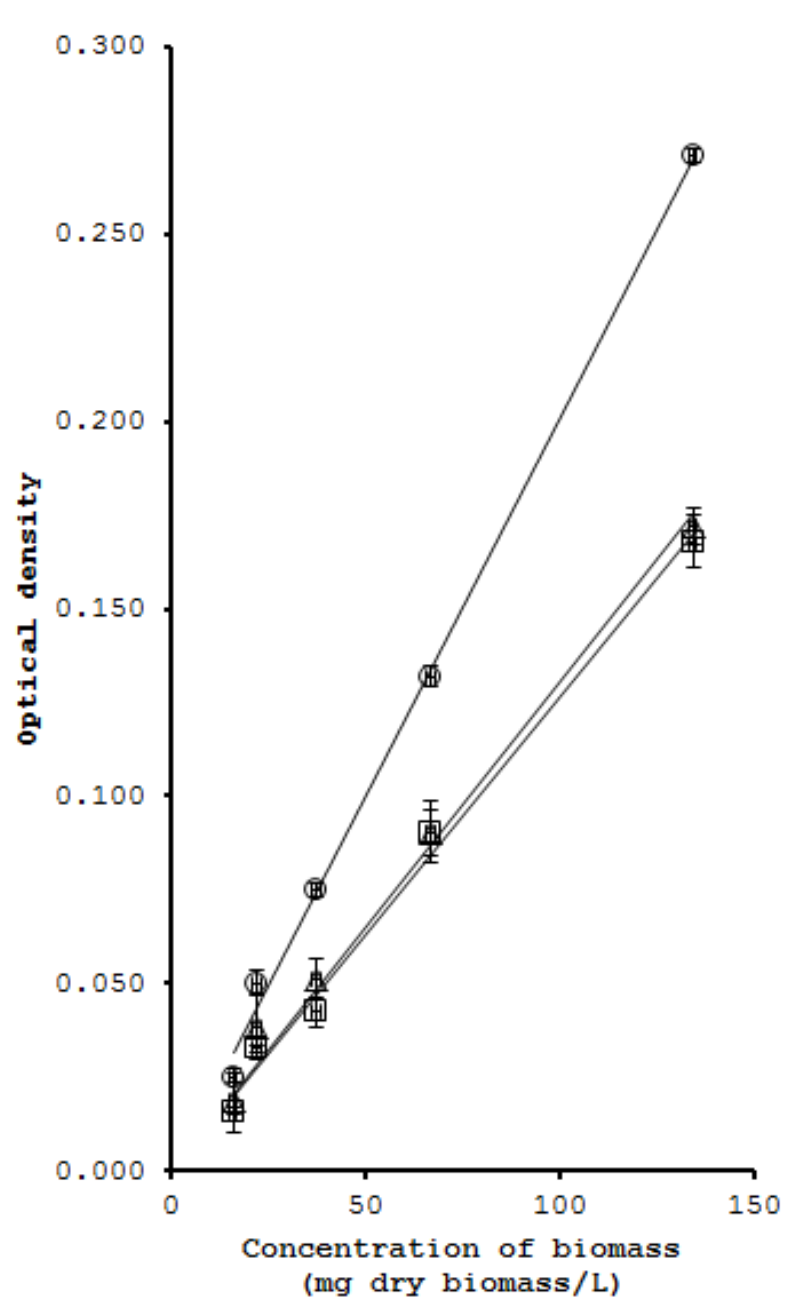

Pseudomonas sp. LMD 38.20

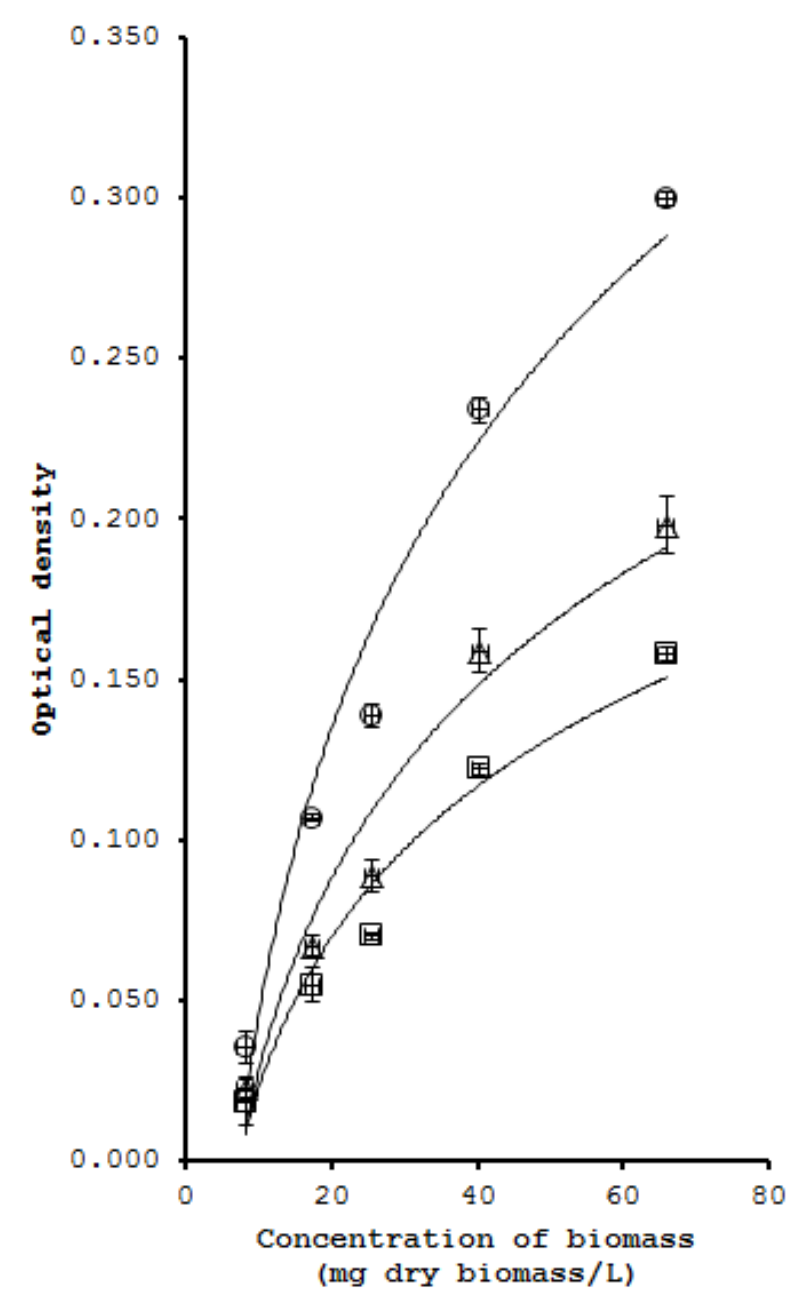

Achromobacter sp. LMD 38.21

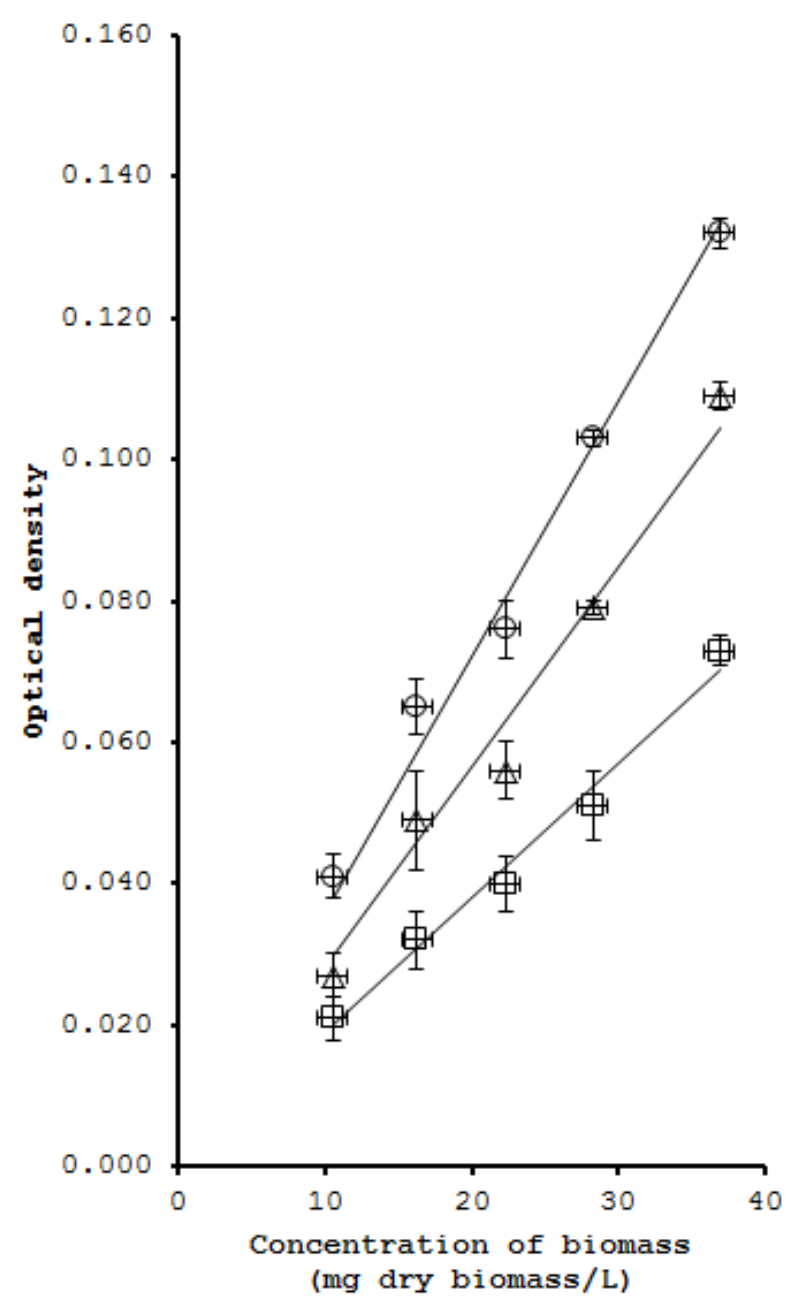

Thermithiobacillus sp. NCIMB 8349 